different institutions in the survey. The highest crude death rate was twenty-three times the lowest, and this cannot be entirely due to differences in the type of patient at the hospitals involved. A study of the reasons for these variations might also produce some interesting results.

\section{Organisms for Biology Teaching}

The boom in biology teaching in British schools, together with the spate of interest in new curricula, has created curious and somewhat unexpected shortages of organisms for students to dissect or otherwise to use. Professor J. W. S. Pringle pointed out, at the British Association last week, that the demands of biology teaching had themselves helped to reduce the size of populations of frogs in Britain, though it is likely that the increasing urbanization of the country side and the difficulty of persuading men to collect wild frogs have contributed to the difficulties of the biological suppliers in meeting - at an economic pricethe demands of the schools. Fortunately there is the promise of a substitute for the frog; the South African clawed toad, Xenopus laevis, is as suitable for dissection by juveniles, and has the added virtue that it can be bred in the laboratory, and that the tadpoles-which are almost transparent-are valuable object lessons in development. Precisely these advantages account for the popularity in recent years of the locust as an experimental creature. In the long run, however, the supply of traditional organisms for teaching is likely to be less of a problem than the need to supply unfamiliar organisms. Biological suppliers, and some schools, have been hard pressed in recent years to know how best to handle distinctive mutants of a species of yeast used in a genetical study as part of the biology programme of the Nuffield Science Teaching Project, because one of the mutants tends to revert to the other. Problems like these are bound to become more common in the years ahead.

Fortunately, some of the difficulties seem to have been fully anticipated. The Institute of Biology, independently and through the joint committee on biological education with the Royal Society, is but one of the organizations to have directed attention to the problem. The ideal outcome is a greater awareness among the biological suppliers of the needs of the schools, and a willingness to spend money on development, not merely of methods of culture but techniques of distribution as well. Another prerequisite of good management is that schools and school authorities should be prepared to pay the real cost of the more sophisticated service which the new curricula will require, and not just what it used to cost to supply each half a dozen pupils with a dogfish and a dozen frogs. In the long run, of course, it would be splendid if the universities - which have similar problems on a more exalted level-could keep an avuncular eye on what is happening in the schools.

\section{European Biochemistry}

THE Federation of European Biochemical Societies (FEBS) was founded three years ago with the aim of promoting closer contact and co-operation among European biochemists. The federation is governed by a Council of delegates from the constituent societies which meets under the chairmanship of the delegate of the society responsible for organizing the next general meeting. So far, these meetings have been held annually, in London (1964), Vienna (1965) and Warsaw (1966).

The third annual meeting was organized for the federation by the Polish Biochemical Society and was held during April 4-7, 1966, in Warsaw, under the chairmanship of Professor K. Zakrzewski. The meeting was the largest held in Warsaw in recent years and was attended by 1,571 biochemists, of whom 545 came from Poland, 993 from other European countries and thirty-three from overseas, including three from China. The scientific programme consisted of an inaugural lecture by Professor P. Grabar (Paris) entitled "L'immunochimie des proteines", thirty-eight invited lectures given in a symposium on "Properties and Functions of Genetic Elements" and two colloquia, one on "The Biochemistry of Blood Platelets", the other on "The Biochemistry of Mitochondria", and 525 free papers. The contributions to the symposium and colloquia are to be published jointly in November of this year by Academic Press, Ltd., London, and Polish Scientific Publishers, Warsaw. It would be invidious to select for special mention any particular contributions from the large number of papers presented at this meeting. There is little doubt, however, that, provided the present high standard is maintained in future years, the annual FEBS meeting will quickly achieve recognition as one of the most important scientific events for European biochemists.

The federation is also active in directions other than the annual meetings. A programme of summer schools began in 1965 with Professor H. R. V. Arnstein as chairman of the organizing sub-committee. The 1966 programme involved schools at University College, London, on "Mechanisms of Enzyme Action", organized by Dr. B. R. Rabin, and at the University of Uppsala on "Separation and Fractionation of Macromolecules and Particles", organized by Professor A. Tiselius and Professor J. Porath. Financial support for these schools has been given by the European Molecular Biology Organization, the Council of Europe, the Royal Society of London and the British Council. In 1967 there will be two schools, one on "Steroid Biochemistry", organized by Dr. J. K. Grant, which will be held in Glasgow during April 3-14, and the other on "Nucleic Acids", which will be held in Marseilles during September 11-16 under the direction of Dr. M. Grunberg-Manago and Professor R. Monier. Details of the schools are advertised in the bi-annual FEBS Bulletin, distributed to all societies in the federation.

The council of the federation, meeting in Warsaw, has taken a major decision to enter the publishing field with a general journal of biochemistry. This is planned to appear early in 1967 and has Sir Hans Krebs as honorary chairman, with Professor C. Liébecq as editor-in-chief, and the support of senior European biochemists as editors and advisers. The appearance of the journal will not, however, add to the number of such publications, since an agreement has been reached whereby the new publication will succeed an existing biochemical journal.

Information about the activities of the federation can be obtained from the Secretary-General, Professor W. J. Whelan, Royal Free Hospital School of Medicine, 8 Hunter Street, London, W.C.1. 